\title{
Comunicación

\section{En busca del entretenimiento: televisión $y$ audiencia juvenil en la frontera norte}

\author{
DAVID GONZÁLEZ HERNÁNDEZ*
}

Este artículo ofrece un análisis intercultural de la recepción televisiva estadounidense y mexicana entre los jóvenes de la ciudad de Tijuana mediante la exploración de la subjetividad, así como una descripción de la oferta televisiva en la frontera. Lo anterior, busca enfatizar el potencial y papel legitimador, especialmente de entretenimiento, que conllevan los programas estadounidenses en la configuración de la cultura televisiva en la frontera, estructurada, en este caso, mediante interacciones trasfronterizas en tiempos de globalización.

PALABRAS CLAVE: televisión, recepción intercultural, jóvenes, frontera.
This article offers an intercultural reception analysis of American and Mexican television programs between young viewers of the city of Tijuana, as well as a description of the television offering in the border with the U.S. throughout this presentation I emphasize the potential and legitimize role, especially of entertainment, that entail the American programs in the configuration of young people television culture in the border, in this case, by means of cross-border mediated interaction.

KEY WORDS: television, intercultural reception, young people, border.

* Universidad Autónoma de Baja California, campus Tijuana.

Correo electrónico: deived2340@yahoo.com.mx 


\section{INTRODUCCIÓN}

En la ciudad de Tijuana la audiencia experimenta una televidencia particular. La condición de frontera implica, entre otras dimensiones, la existencia de procesos de trasformación sociocultural estructuradas por distintas modalidades históricas, económicas y políticas trasfronterizas. Los fenómenos complejizan su entendimiento si consideramos la mediación de las tecnologías de comunicación masiva, su puesta en circulación de contenidos y el consumo en la región. Entendimiento que presenta numerosas lagunas de conocimiento en los estudios sobre oferta televisiva y recepción en México.

Esto ha provocado, en parte, dos situaciones: por un lado, la continua discusión sobre los diversos enfoques en los estudios de flujo de comunicación trasnacional y de recepción, que implican un crecimiento de los análisis y diagnósticos sobre oferta y consumo en los últimos años (Lozano, 2000); por otro, el imperativo de trascender las categorías tradicionales para ampliar la comprensión de la magnitud del fenómeno. Por lo menos en el caso de la frontera México-Estados Unidos, esta situación impone considerar los dos siguientes puntos generales.

El primero refiere a los estudios de flujo y agenda televisiva, éstos resultan insuficientes cuando sólo consideran las horas de trasmisión, los canales, la cantidad de programas y el origen de la programación. El idioma, la patente de formato televisivo y el material audiovisual plantean aspectos que ayudan en la explicación de las «cercanías» y «alejamientos» culturales, las nuevas formas de hacer televisión con involucramiento directo de productoras extranjeras, y especifican y concretizan la constitución de algunos programas con «sabor mexicano», pero de contenido foráneo respectivamente. Solamente la categoría idioma, representa que el lenguaje utilizado no sea, en principio, una barrera que resienta el atractivo de la programación: Univisión y Telemundo (empresas estadounidenses) en el manejo del idioma español en sus trasmisiones, entremezclan valores, creencias y patrones de conducta «latinos» y estadounidenses.

El segundo lugar resulta de la necesidad de elaborar argumentaciones sobre la relación entre la televisión y la audiencia que escapen a la centralidad de la categoría de «reproducción ideológica»; una tradición 
intelectual que aún predomina en los estudios sobre los contenidos extranjeros en televisión, pero insuficiente para explicar bajo qué circunstancias una determinada audiencia situada en la frontera produce decodificaciones oposicionales sobre la televisión de México (sobre todo) y Estados Unidos.

Este artículo propone analizar la agenda televisiva en la frontera y la recepción de los jóvenes tijuanenses mediante la exploración de la subjetividad, en específico, de esquemas interpretativos. En él se reúne información empírica que pretende comprender la especificidad mediática-trasfronteriza en la interacción entre la audiencia juvenil y la oferta programática televisiva, enfatizando el papel legitimador de entretenimiento estadounidense en la configuración de la cultura televisiva en la frontera.

\section{EL ASPECTO TRASFRONTERIZO \\ EN LA INTERACCIÓN ENTRE AUDIENCIA \\ Y OFERTA TELEVISIVA}

Planteo con interés el término «trasfronterizo« porque, aunque es un término polisémico en su uso desde una variedad de disciplinas, describe características importantes de los procesos a los cuales refiere y que dan cuenta de ciertas dinámicas económico-sociales específicas que ligan a Tijuana con un crecimiento relacionado con una lógica externa: a) la trascendencia de las escalas territoriales que los procesos necesitan para desarrollarse; $b$ ) el origen y destino de los flujos que cada dinámica experimenta en su dirección; $c$ ) la intensidad que cada proceso presenta; d) la frecuencia con que ocurren los fenómenos, y $e$ ) las personas $\mathrm{u}$ objetos involucrados en los procesos (Alegría, 1992).

Precisamente, este vínculo (asimétrico) que expresa lo económico y social, no puede lograse enfocando solamente a las dos economías en interacción. Planteo lo anterior con el propósito de ubicar algunos elementos heurísticos que nos puedan ayudar a entender la dinámica de esas relaciones, y para resaltar la idea principal que refiere a la «interacción« de la región fronteriza, un concepto necesario pero no suficiente, donde las diferencias entre Tijuana y San Diego no introducen una ruptura sino una continuidad estratificada de la estructura social binacional 
(Bustamante, 1989: 41). Así, podríamos entender en cierto nivel que Tijuana se define por macroprocesos trasnacionales y trasfronterizos, al menos en ciertos niveles socioeconómicos, debido a su carácter de frontera que, en última instancia, dan cuenta de la internacionalidad de la vida en esta región.

Una relación que tiene un trasfondo de intercambios comerciales y culturales cotidianos traducidos en lo que puede denominarse como la influencia cultural norteamericana. En este aspecto, el hallazgo de García Canclini (1990) refiere a la intensidad con que los tijuanenses viven la desigualdad de la frontera, y que resulta de tener una imagen menos idealizada que quienes consumen mensajes televisivos en el interior del país. Y este aspecto permite pensar el papel del ámbito trasfronterizo en algunos puntos de interacción social.

En este sentido, Valenzuela Arce (1993) ha reflexionado sobre el consumo simbólico de los jóvenes tijuanenses a partir de ámbitos espaciales de interacción social, mismos que ejercen influencia en la configuración de las relaciones sociales o en las identidades imaginarias. Estos ámbitos los categoriza, siguiendo a la socióloga Agnes Heller, en ámbitos cotidianos (las relaciones estrechas entre sujetos que diariamente confrontan su subjetividad por medio de condicionantes étnicas, de género, de clase, etc.); ámbitos imaginarios (las relaciones amplias de reconocimiento, redes genéricas de significado que influyen sobre la acción colectiva, cuyos significados son puestos en circulación, de manera frecuente, por los medios de comunicación), y el ámbito trasfronterizo. Es en esta última categoría donde concentro esta exposición, ya que refiere mucho a la condición fronteriza y, particularmente, a la ciudad de Tijuana.

La colindancia de Tijuana con el sur de Estados Unidos supone un rasgo que participa de manera importante en la determinación de la «especificidad de las interacciones que se presentan» (Bustamante, 1989: 387), como la vivencia de la desigualdad que había referido García Canclini en el sentido de que los códigos estadounidenses recodifican los contrastes en distintos ámbitos, pero también, como apunta Valenzuela Arce, las semejanzas y los anhelos asimilacionistas, aunque con la advertencia de que estos procesos no implican de manera automática la aculturación, pues también reconoce los procesos de resistencia y conflicto. Así, el ámbito trasfronterizo reconoce en primera instancia el 
ámbito cotidiano cuando se construyen, en este nivel, redes de significado donde se «adscribe« la población de ambos lados de la frontera; esto es posible con la interacción frecuente e intensa y la participación de redes de consumo simbólico trasfronterizo, tales como la radio o la televisión, donde de acuerdo al ámbito de interacción, se tiene un acceso e incorporación desigual. En segundo lugar, Valenzuela ubica las diferencias culturales, como los lenguajes, prejuicios, estereotipos, racismo, adscripciones imaginarias, diferencias de poder, etc. Así, para Valenzuela, muchos jóvenes incorporan a San Diego o la región sur de Estado Unidos en sus ámbitos cotidianos de interacción, lo cual expresa un saber y una adherencia a redes de significado definidas por la condición trasfronteriza.

Además, con el desarrollo de los medios de comunicación, en particular de la televisión, se ha intensificado un espacio constituido por complejos procesos de significación que incorporan códigos mexicanos y estadounidenses. La televisión, en este sentido, construye los sentidos sociales y las redes de significado que recurrentemente se enfrentan, elaboran, reelaboran y decodifican en las experiencias de vida de grupos sociales. En suma, la trasmisión televisiva en Tijuana comprende un ámbito trasfronterizo, donde convergen imágenes producidas en ambos lados de la frontera y que se pueden sintonizar en Tijuana, como territorio mexicano, y/o en San Ysidro, Chula Vista, National City, San Diego, La Joya, Del Mar, entre otras, como región estadounidense.

\section{OFERTA TELEVISIVA}

EN LA FRONTERA NORTE

Actualmente persisten las preocupaciones que genera la magnitud del desequilibrio en los flujos de comunicación entre México y Estados Unidos. En primer lugar, se mantiene un malestar cultural en las consecuencias que provocan los contenidos extranjeros en la modificación y erosión de valores, costumbres y formas de vida en el país. En segundo lugar, una preocupación política y económica que se despliega del primero: un debate de soberanía e integridad nacional (Lull, 1997), como los esfuerzos por establecer un Nuevo Orden Mundial de la Información y la Comunicación (NOMIC). Debate muy pertinente frente al comienzo 
de una nueva era, que trasciende a las meras negociaciones comerciales o la modernidad (Giddens, 1994), y clave si lo ubicamos en el marco del Tratado de Libre Comercio (TLC) entre Estados Unidos, Canadá y México. Esta preocupación de académicos e intelectuales ha reflexionado, yendo más allá de la noción de imperialismo cultural, en el «nuevo» carácter de la integración global como forma de dependencia, en el caso del espacio audiovisual mexicano, contemplado como altamente «interdependiente» con el estadounidense (Sánchez Ruiz, 1996).

Una forma de evaluar las condiciones que favorecen el flujo asimétrico ha sido el diagnóstico de la oferta mediante el estudio de la programación televisiva. De acuerdo con Giddens (1995), estas programaciones televisivas conforman la estructura de significación como parte importante de la cultura regional. De esta manera, la presencia de programas televisivos estadounidenses en Tijuana son concebidos como insumos de procesos de comunicación o como

nudos que integran y plantean resultados, imágenes o símbolos de una información condensada, producto de una infinidad de intereses de todo tipo, de grupos y compañías productoras y comercializadoras de la programación audiovisual (Ibarra, 1998: 142).

De acuerdo a un estudio que realicé en 2002 sobre programación en la televisión abierta en México (canal 2, XHGC canal 5 y Galavisión de Televisa; canal 7 y 13 de TV Azteca, todos ellos privados), particularmente sobre el origen de la programación, el porcentaje de programas estadounidenses trasmitidos durante una semana, sumaba un total de 43.1\%. El porcentaje aumentaba cuando agregaba otras categorías a los programas, por ejemplo, cuando el formato original patentado fuera estadounidense (el caso de «Family Feud» como formato original y «Cien mexicanos dijeron» como formato adaptado). La numeración se incrementa hasta $52.6 \%$ al incluir la categoría de productos audiovisuales o, mejor dicho, programas cuyo material audiovisual fuera de Estados Unidos, tal fue el caso de «Picante y caliente», «iAy caramba!» $\mathrm{y}$ «Riesgo total», como muestras representativas.

Muchos investigadores han llegado a conclusiones similares en cuanto al porcentaje de programación extranjera trasmitida por la te- 
levisión abierta mexicana: en general, hay una enorme diferencia en la proporción de lo que se produce y lo que se importa, y la mayor parte se orienta al entretenimiento, especialmente dibujos animados y comedias de situación. Son los géneros más constantes los que abarcan $81.8 \%$ de la programación del canal 5, por ejemplo: esto describe la función del canal como mera programadora.

En la oferta televisiva en la frontera Tijuana-San Diego los porcentajes cambian sustancialmente. En el estudio realizado en 2002 ubiqué la presencia de producción televisiva en México, con las categorías de origen y cantidad de programación como ejes de análisis. En noviembre de 2003 analicé la programación televisiva trasmitida en la zona urbana de Tijuana. El enfoque partió de la programación, pero incluí otro elemento analítico: las horas de trasmisión. La muestra fue una semana de noviembre y la fuente fueron las revistas TV Guide y Tele Guía, así como las páginas virtuales de cada televisora.

En cuanto al universo de análisis de la trasmisión televisiva, determiné trabajar sólo con los canales de televisión abierta, que por sus características técnicas y socioeconómicas se encuentran al alcance de un segmento de población de estrato medio, considerando el rango de horario en el que la mayoría de los jóvenes tiene posibilidad o ve televisión, es decir, de 6:00 de la mañana a 12:00 de la noche; ya que 14 de los 15 canales trasmiten las 24 horas (véase cuadro 1 ).

Durante la semana estudiada, el total de horas trasmitidas en señal abierta de los canales fue de 2646 horas (158 760 minutos). A partir de ese total contemplamos, en el horario de 6:00 am a 12:00 am, 1884 horas (113 040 minutos). De ese total, más de 60\% (1 139 horas) se produce fuera del país. El perfil general de la señal abierta en la frontera es muy variado, ya que combina distintos géneros, desde las comedias de situación, programas dedicados a los jóvenes, pasando por los programas sensacionalistas, noticias y variedades, hasta educativos, películas y reportajes.

El cuadro 2 ofrece una panorámica de los tres principales perfiles programáticos que oferta cada canal, además de mostrar fundamentalmente la lógica de programación por cada canal visto en la ciudad de Tijuana. La clasificación de los géneros televisivos tuvo mínimas consideraciones, en parte porque las categorías varían en los diagnósticos 


\section{CUADRO 1}

CANALES DE TELEVISIÓN VISTOS EN TIJUANA POR SEÑAL ABIERTA

\begin{tabular}{|c|c|c|c|c|}
\hline Canal & $\begin{array}{l}\text { Empresa o } \\
\text { afiliación }\end{array}$ & $\begin{array}{l}\text { Horas de } \\
\text { trasmisión }\end{array}$ & Cobertura & Nacionalidad \\
\hline 3 & IPN Canal 11 & 24 & $\begin{array}{l}\text { Nacional } \\
\text { (ciertos lugares); }\end{array}$ & Mexicana \\
\hline 6 & Fox & 24 & $\begin{array}{l}\text { Nacional/ } \\
\text { regional/local }\end{array}$ & Estadounidense \\
\hline 8 & CBS & 24 & $\begin{array}{l}\text { Nacional/ } \\
\text { regional/local }\end{array}$ & Estadounidense \\
\hline 10 & $\mathrm{ABC}$ & 24 & $\begin{array}{l}\text { Nacional/ } \\
\text { regional/local }\end{array}$ & Estadounidense \\
\hline 12 & $\begin{array}{l}\text { Televisa } \\
\text { (local) }\end{array}$ & 24 & $\begin{array}{l}\text { Nacional/ } \\
\text { regional/local }\end{array}$ & Mexicana \\
\hline 15 & PBS & 24 & $\begin{array}{l}\text { Nacional/ } \\
\text { regional/local }\end{array}$ & Estadounidense \\
\hline 21 & TV Azteca 7 & 24 & Nacional & Mexicana \\
\hline 27 & TV Azteca 13 & 24 & Nacional & Mexicana \\
\hline 33 & Telemundo & 24 & $\begin{array}{l}\text { Nacional/ } \\
\text { regional/local }\end{array}$ & Estadounidense \\
\hline 36 & Univisión & 24 & $\begin{array}{l}\text { Nacional/ } \\
\text { regional/local }\end{array}$ & Estadounidense \\
\hline 39 & NBC & 24 & $\begin{array}{l}\text { Nacional/ } \\
\text { regional/local }\end{array}$ & Estadounidense \\
\hline 45 & $\begin{array}{l}\text { Independiente/ } \\
\text { Galavisión }\end{array}$ & 18 & $\begin{array}{l}\text { Nacional/ } \\
\text { regional/local }\end{array}$ & Mexicana \\
\hline 51 & $\begin{array}{l}\text { Independiente- } \\
\text { OPN }\end{array}$ & 24 & regional/local & Estadounidense \\
\hline 57 & Televisa XEW & 24 & Nacional & Mexicana \\
\hline 69 & $\begin{array}{l}\text { Warner } \\
\text { Brothers }\end{array}$ & 24 & $\begin{array}{l}\text { Nacional/ } \\
\text { regional/local }\end{array}$ & Estadounidense \\
\hline
\end{tabular}

de programación. Cada categoría designa programas con formatos conocidos identificados por su estructura narrativa o contenido. Aquí me limito a objetivar algunos géneros televisivos en términos amplios; no problematizo en profundidad debido al desvío que puede presentar la 
perspectiva de estudio: la distribución de la oferta televisiva en la frontera. No obstante, dos aclaraciones son pertinentes para la clasificación de géneros. La primera refiere al género del humor. En este estudio elaboro dos distinciones generales: a) las comedias de situación: programas caracterizados por producirse en forma seriada, cuentan historias consecutivas en la mayoría de los casos, el uso que hacen del humor es a partir de colocar los mismos personajes en situaciones absurdas, y $b$ ) los programas cómicos mexicanos: programas que basan su comicidad en los actores mediante la producción de diálogos y chistes a partir del uso del doble sentido o albur.

La segunda aclaración tiene que ver con el idioma. La cuestión del origen de la programación plantea conocer el idioma en el cual se trasmite, al menos en la frontera, debido a que tanto Univisión como Telemundo (empresas estadounidenses) manejan el idioma español en su programación. Así, cuando hablamos de programación estadounidense, necesariamente debemos referirnos al idioma que utilizan si consideramos la audiencia y su cercanía cultural. Por ejemplo, en la oferta televisiva de la frontera, $10 \%$ corresponde a las telenovelas (véase cuadro 3 ). Del mismo $10 \%$, casi $75 \%$ es de origen mexicano o hispano (es decir, $15 \%$ de las telenovelas en la frontera son estadounidenses), sin embargo, de $75 \%$ de las telenovelas en español, 33\%, de manera conjunta, pertenecen a la cadena de Univisión y Telemundo.

A manera global, todos los géneros televisivos tienen un buen tiempo en el aire, sin embargo, predominan las noticias como primer perfil de los canales que trasmiten en la frontera (véanse cuadros 2 y 3). El género de comedias de situación predomina en el canal 6 de Fox, con el primer lugar (46 horas a la semana); en el 69, de Warner Brothers, como segundo (35 horas y media), y es el tercer perfil en programación del canal 21 de TV Azteca (siete horas y media). No obstante, si vamos al balance global en los resultados del cuadro 3, las comedias de situación ocupan el lugar sexto de la programación ofertada en la frontera.

El cuadro 3 presenta el panorama global de la programación en la frontera. En principio destaca el hecho de que ningún género televisivo sobrepasa $15 \%$ del total, lo que señala que si bien hay una oferta considerable de opciones, la distancia entre una y otra oferta televisiva es mínima. Así mismo, el cuadro 3 muestra el porcentaje que corresponde a la 


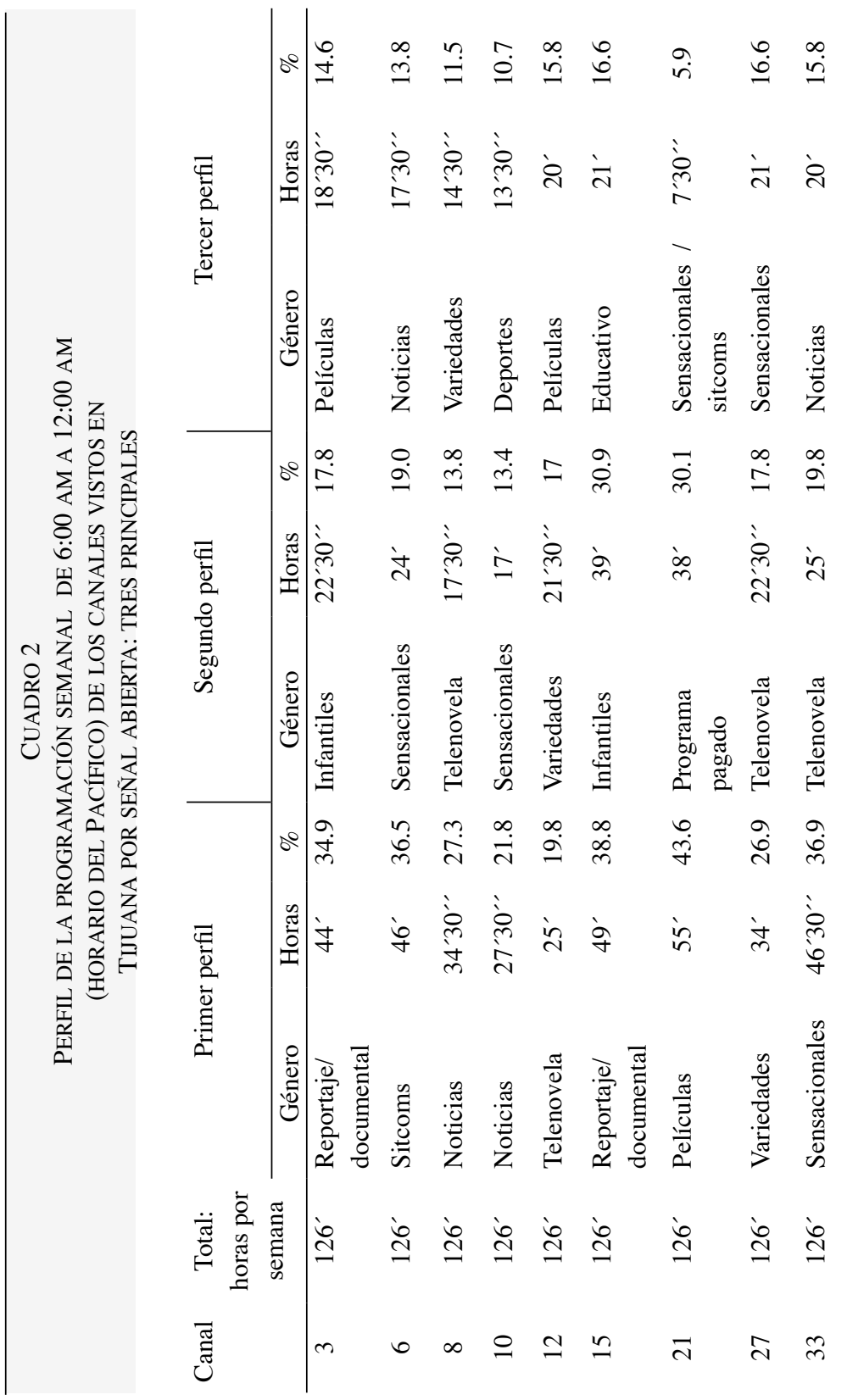




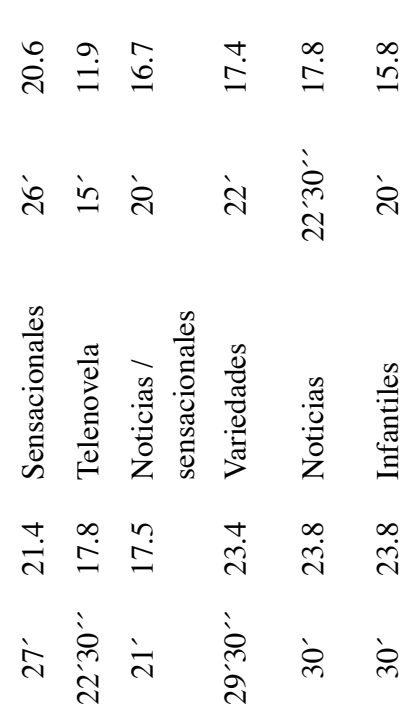

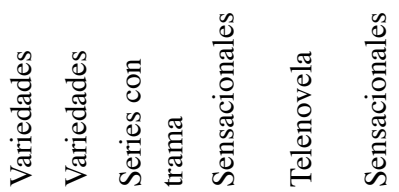

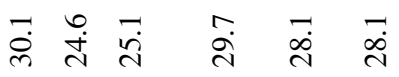

i ‘

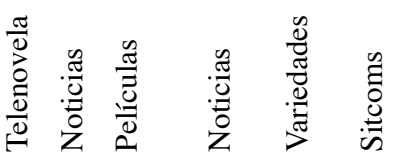

i。

ले $\frac{7}{7}$ in 


\begin{tabular}{|c|c|c|c|c|c|}
\hline \multicolumn{6}{|c|}{$\begin{array}{c}\text { CUADRO } 3 \\
\text { PORCENTAJE GLOBAL POR GÉNERO TELEVISIVO } \\
\text { SOBRE LA OFERTA EN LA FRONTERA }\end{array}$} \\
\hline \multirow[t]{2}{*}{ Lugar } & \multirow{2}{*}{$\begin{array}{l}\text { Género } \\
\text { televisivo }\end{array}$} & \multirow{2}{*}{$\begin{array}{l}\text { Porcentaje } \\
\text { global }\end{array}$} & \multirow{2}{*}{$\begin{array}{l}\text { Porcentaje } \\
\text { en inglés }\end{array}$} & \multicolumn{2}{|c|}{ Porcentaje en español } \\
\hline & & & & & $\begin{array}{c}\text { Aportación } \\
\text { de } \\
\text { Univisión y } \\
\text { Telemundo* }\end{array}$ \\
\hline 1. & $\begin{array}{l}\text { Noticias / } \\
\text { informativos }\end{array}$ & 14.80 & 59.00 & 41.00 & 11.50 \\
\hline 2. & $\begin{array}{l}\text { Sensacionales } \\
\text { / reality } \\
\text { shows }\end{array}$ & 13.90 & 47.00 & 53.00 & 27.60 \\
\hline 3. & Variedades & 11.20 & 39.00 & 61.00 & 15.80 \\
\hline 4. & Telenovelas & 10.00 & 25.30 & 74.70 & 33.50 \\
\hline 5. & Películas & 9.60 & 17.00 & 83.00 & 9.90 \\
\hline 6. & Sitcoms & 7.10 & 86.00 & 14.00 & 0.00 \\
\hline 7. & $\begin{array}{l}\text { Reportajes/ } \\
\text { documentales }\end{array}$ & 6.90 & 54.00 & 46.00 & 1.10 \\
\hline 8. & Caricaturas & 6.50 & $61.00 \%$ & 39.00 & 6.00 \\
\hline 9. & Deportes & 5.50 & 47.00 & 53.00 & 6.70 \\
\hline 10. & $\begin{array}{l}\text { Series } \\
\text { dramáticas }\end{array}$ & 5.00 & 56.00 & 44.00 & 8 \\
\hline 11. & $\begin{array}{l}\text { Programa } \\
\text { pagado }\end{array}$ & 4.50 & 30.00 & 70.00 & 1.70 \\
\hline 12. & Concursos & 2.10 & 67.00 & 33.00 & 12.50 \\
\hline 13. & Educativos & 1.30 & 87.00 & 13.00 & 0.00 \\
\hline 14. & $\begin{array}{l}\text { Debates o } \\
\text { análisis }\end{array}$ & 1.00 & 0.00 & 100 & 0.00 \\
\hline 15 . & $\begin{array}{l}\text { Programa } \\
\text { cómico } \\
\text { mexicano }\end{array}$ & 0.60 & 0.00 & 100 & 50 \\
\hline
\end{tabular}

* Nota: El porcentaje que indica esta columna corresponde a su aportación al total del porcentaje en español. 
producción mexicana y estadounidense. La categoría que permite distinguir este aspecto es el idioma, por eso distingo el porcentaje que aportan al total las cadenas Univisión y Telemundo, para tener una visión más precisa de la distribución televisiva. Así, la oferta programática que predomina en la frontera son los noticieros, con $14.8 \%$ global (278 horas y media a la semana), donde casi $60 \%$ (164 horas) es de origen estadounidense.

Lo anterior es significativo si consideramos que casi $95 \%$ de la producción local es oferta informativa. La producción local representa $7.9 \%$ (150 horas y media) de la programación global en la frontera. De ese porcentaje sólo 10\% (16 horas) es de origen mexicano, es decir, hay poca producción local en Tijuana: basta decir que el canal 12 de Televisa produce casi $60 \%$ del total local, lo que implica la función de las televisoras locales mexicanas como retrasmisoras de la programación del centro del país. En este sentido, destaca el lugar quinto ocupado por las películas, con $9.6 \%$ del global, donde $83 \%$ de esa porción es ofertado por los canales locales en español.

Como he señalado, el género de las comedias de situación ocupó el sexto lugar global. Su porcentaje es $7.1 \%$ del total (135 horas: 8 100 minutos). Cabe aclarar que 14\% (18 horas y media) que aportan los canales mexicanos al total, son programas doblados al español. En resumen, puedo afirmar que los canales vistos por señal abierta en Tijuana, en cuanto a la programación de comedias de situación, planean, en mayor o menor medida, su programación dependiendo del perfil juvenil (el atardecer y parte de la noche), sea norteamericano, hispano o mexicano. La fragmentación de los porcentajes por género televisivo orienta a percibir la variedad y las opciones programáticas que se tienen en la frontera, aspecto importante en la elección y legitimidad de la televisión estadounidense sobre la mexicana, como muestro en el tercer apartado.

\section{ESQUEMAS INTERPRETATIVOS}

DE LA AUDIENCIA JUVENIL: JUEGO DE OPOSICIONES

El análisis de los esquemas remiten a los repertorios interpretativos de la audiencia. Los repertorios interpretativos, inteligibles mediante representaciones discursivas, exponen cómo las personas dan cuenta de 
sí mismas y del grupo social primario o secundario al que pertenecen como jóvenes. Utilizo este concepto en lugar de «comunidades interpretativas», pues presenta algunas problemáticas. El tránsito entre la definición de comunidades interpretativas a repertorios interpretativos fue resuelto, en cierta medida por Klaus B. Jensen al considerar otro criterio, además del socioeconómico o demográfico, que relaciona y pone en relieve la construcción del significado (más que la adherencia o membresía a un segmento social o estilo de vida). Esta construcción de significados refiere en un apartado cognoscitivo a lo que Jensen (1987) denomina como los «factores analíticos», que considera la capacidad de expresión y perceptiva de las configuraciones específicas de los televidentes, de sus gratificaciones buscadas, sus experiencias y gustos personales.

Para esta parte presento resultados de un grupo de discusión realizado con personas jóvenes (18-23 años) nativos de Tijuana y de estrato socioeconómico medio. La finalidad fue tener acceso a un discurso que pudiera dar cuenta, con mayor densidad, de las formas de representación predominante de una generación que ha vivido toda su existencia en la frontera, que implicó para propósito del estudio, mayor exposición a la oferta televisiva norteamericana y un cúmulo de información sobre las interacciones individuales con el país vecino gracias a posibilidades de cruce y acceso a ofertas del otro lado de la frontera.

La semiótica permitió profundizar sistemáticamente en el discurso-relato, elaborado grupalmente, al abordarlo como texto, es decir, como una organización donde operan varios sistemas semióticos y como el lugar donde se trabaja la «formalización del sentido» (Regui1lo, 1995: 66) o el «simulacro de la generación del sentido» (Juárez, 1992:49). El apoyo analítico convino mediante la construcción de cuadrados semióticos.

Un supuesto importante para el análisis fue considerar la frontera norte como un lugar desde el cual se viven oposiciones de manera más intensas por condiciones socioculturales propias de la ciudad: entre la televisión mexicana y la norteamericana, entre México y Tijuana, entre Tijuana y Estados Unidos, entre nativos tijuanenses y personas migrantes, etc.; en fin, como un lugar desde el cual se contemplan «distintas diferencias». 
Hay cinco tipos de relación que cobraron vida en el discurso, y quedaron organizados bajo categorías que se enfrentan: $a$ ) joven tijuanense $v s$. adulto tijuanense; $b$ ) joven televidente $v s$. joven no televidente; $c$ ) televisión norteamericana vs. televisión mexicana; $d$ ) humor televisivo americano $v s$. humor televisivo mexicano, y $e$ ) noticieros estadounidenses vs. noticieros mexicanos. Los fragmentos de diálogo entre los jóvenes ilustran el amplio margen de oposición que caracteriza la relación de los jóvenes con la oferta televisiva norteamericana.

\section{Joven tijuanense versus adulto tijuanense}

Los jóvenes tijuanenses asumen que los adultos que habitan la ciudad de Tijuana probablemente son del interior del país, que llegan con creencias rígidas. Y los jóvenes se presentan en conjunto, además, de saber como crecer, con una proyección hacia una construcción identitaria. El joven tijuanense se encuentra en conjunto con estos valores, favorecedores para este actor, y se ubica en oposición al adulto respecto a su relación con Estados Unidos, lo que el objeto influencia parece ser no totalmente deseado. El objeto deseado que opera en tomar lo mejor de Estados Unidos se constituye en la medida que su conjunción daría base para la obtención de otro tipo de calidad de vida en el aspecto cultural. Así, la acción de tomar lo mejor de otro país configura una visión pragmática que se concreta en lo que sirve culturalmente, lo útil de Estados Unidos para los tijuanenses.

Esto equivale a decir que los adultos tijuanenses mantienen la cultura del interior del país que ha sido heredada. A los adultos se les asocia con un conjunto con valores que para los jóvenes participantes no les favorecen mucho, pues se ubican en oposición a ellos y que subsume otros valores especificados por oposición en el discurso: rígidos, crecieron de una sola forma que les fue heredada, y no son realmente de Tijuana sino migrantes que se asentaron en esta ciudad. Por otro lado, el joven tijuanense se relaciona con el cambio, con una construcción conciente de la identidad que refiere a un pragmatismo cultural a fin de mejorar, en un marco muy general, la calidad de vida en la frontera.

El gráfico 1 supone un resumen narrativo de esta visión mediante los ejes de oposición. 


\section{GRÁFICO 1}

JOVEN TIJUANENSE VERSUS ADULTO TIJUANENSE

Cambio

Construcción identitaria

Pragmatismo
Rigidez

Migrante

Herencia cultural

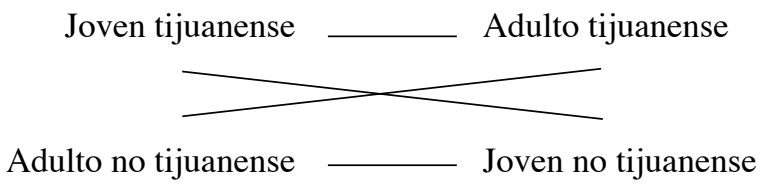

Flexible

Homogéneo

Nativo

Tradicional

Cosmopolita

Infructuoso

\section{Joven televidente versus joven no televidente}

El joven televidente se asocia con la diversión, además ha aprendido a serlo. El agente es un actor distinto en cuanto a su televidencia que supone un estado de conjunción eufórica, lúdica y de entretención en este caso. Lo anterior supone que los jóvenes no televidentes de la oferta televisiva de origen norteamericano, están en disyunción con la diversión, formación y comprensión como agentes «ay, no lo veo porque no le entiendo». Queda explícito, entonces, que no saber el idioma inglés se opone a la entretención, educación y entendimiento, una conjunción disfórica. Aparece aquí una modalidad articulada por el saber, «cómo te va a entretener algo que no entiendes», de esta manera, parece que el saber el idioma y entender la cultura norteamericana, en la esfera de la televidencia se contrapone a los saberes y competencias de la no audiencia recurrente de la televisión estadounidense.

En este aspecto, hay reglas o procedimientos que permiten la intelección de la audiencia en tanto sujetos competentes para la diversión y supone un recorrido narrativo de esta visión sobre la entretención. La primera tiene que ver con la televidencia, que define la necesidad de un aprendizaje de la televisión, esta regla posibilita detectar la recurrencia 
televisiva y el tipo de interacción de las audiencias juveniles en el sentido de la repetición lúdica. La segunda refiere a la competencia. A pesar de la recurrencia a través de la televidencia, la mayor riqueza es la comprensión de las narraciones televisivas. La televisión norteamericana tiene muchas formas de ver pero pocas de entender, entonces, se recurre a la competencia donde el manejo de códigos «estándar» posibilitan ir más allá de la mera traducción.

\section{Televisión norteamericana versus televisión mexicana}

La televidencia de ambas se concibe como opuesta en cuanto a oferta programática y tecnológica. La televisión norteamericana, se encuentra en conjunción con categoría de más variedad (que la mexicana) y en términos de mejor recepción de la señal. De esta forma, al constatar la no concordia para la televisión mexicana, se presenta un discurso disfórico.

El término de mayor variedad queda establecido por medio de ciertos valores o géneros televisivos que se consideran necesarios para la televisión. Por otra parte, la no variedad, engloba que la televisión mexicana sólo tiene tres géneros: novelas, noticias y deportes. La categoría de televisión norteamericana se opone a la de televisión mexicana (véase gráfico 2). Si se relacionan estas oposiciones, que rigen esta parte del texto, y se articula con el enfrentamiento, surge la siguiente configuración.

\section{GRÁFICO 2}

TELEVISIÓN NORTEAMERICANA VERSUS TELEVISIÓN MEXICANA

Mejor señal

Mala recepción

Tv EU Tv México

Mayor variedad

No gran variedad

Hay entonces una percepción positiva sobre la televisión norteamericana, la cual presenta mejores posibilidades de acceso a sus diversos canales. Por tener este mejor acceso se cuenta con mayor variedad de 
programas televisivos que pertenecen a un campo semántico relacionado con la opción. En este aspecto la oferta televisiva norteamericana es diferente a la mexicana porque hay mayor opción de programas y canales. El rasgo común de esta posibilidad es que obedece a la elección de programas dentro de una compleja agenda televisiva estructurada mediante géneros o estilos. La opción se opone a la sujeción (véase gráfico 3).

GRÁFICO 3
OPCIONES TELEVISIVAS

Opción $\left\{\begin{array}{cc}\text { Mejor señal } & \text { Mala recepción } \\ \text { TV EU ------ TV México } \\ \text { Mayor variedad } & \text { No gran variedad }\end{array}\right\}$ Sujeción

Humor televisivo norteamericano versus humor televisivo mexicano El humor es importante, conforma un gran eje de oposición y razón que articula los motivos de ver la televisión estadounidense. Es importante destacar que mientras el humor televisivo norteamericano es un aliado de la diversión y el entretenimiento, el humor televisivo mexicano, además de representar lo simple y ordinario, plantea aspectos culturales «de allá del interior» para un segmento de la audiencia juvenil tijuanense. Aspectos como el doble sentido, percibido como base de la televisión mexicana, con chistes menores (bajeza).

Lo anterior muestra una concepción no deseada del tipo de televisión desde el punto de vista del entretenimiento. Con todo, se piensa que el humor trasmitido por la televisión mexicana no se presenta en situaciones reales, ya que en el mundo cotidiano se observan enfrentamientos que contradicen la cosmovisión televisiva mexicana. Por otro lado, el humor norteamericano televisivo, es un valor que debe de entenderse para reírse, sin necesidad de explicaciones. Si se recurre a la estructura del cuadrado semiótico para analizar el trabajo de interpreta- 
ción que hizo el grupo, se puede observar como éste afirma el contenido del relato, rescata elementos de conflicto que aparecen en él y se coloca en el eje de creer (esquema siguiente página).

\section{Noticieros norteamericanos versus noticieros mexicanos}

La quinta relación resulta interesante para comprender la relación con los géneros televisivos, en particular el formato informativo. Esta es la última oposición entre programas norteamericanos y programas mexicanos, esto se manifiesta en la isotopía que articula los contenidos de esta visión sobre los noticieros de los dos países (véase gráfica 4). Dicha isotopía de enfrentamiento tiene relevancia en presentar dos maneras distintas de abordar la realidad nacional y regional.

Se indica en el discurso grupal que la televisión estadounidense conforma un objeto deseado de información relacionado con la memoria, o al menos así parece establecer el «seguimiento» de una noticia violenta

\section{GRÁFICO 4}

NOTICIEROS NORTEAMERICANOS VERSUS NOTICIEROS MEXICANOS

Complicado

Elaborado

Humor negro

Imaginativo

Retador
Simple

Incoherente

Doble sentido

Ofensivo

Explícito

ENTRETENIMIENTO Humor TV México
Humor no TV México

Complejo

Situacional

Múltiples interpretaciones

Respetuoso

Ambiguo
Simple

Apático

Humor blanco

Enajenante 
en la televisión, mientras que los noticieros mexicanos «nos han acostumbrado al olvido». Estos elementos sumados apuntan a un sentido de la consciencia social que tiene memoria. Pero una memoria de Estados Unidos en la forma de abordar la noticia. El texto atribuye a los noticieros mexicanos, además de la depresión y el olvido, la violencia, aunque no esté explícitamente formulado se puede inferir cuando se habla de la exageración de «noticias de esas», noticias de robos, balazos y asaltos. En tal sentido, la lógica profunda del texto descansa sobre la memoria social acumulada por la audiencia estadounidense (y fronteriza). No obstante, esta memoria social es activada mediante el reconocimientos de una de las dimensiones más potentes de los noticieros: la espectacularización de la información o «el escándalo que se arma».

Cabe añadir que el texto, en profundidad, constituye la objetivación del valor realidad nacional proyectado desde la noticia, que atribuyen los sujetos a lo que se informa y sus cualidades. Hay un gusto de los noticieros estadounidenses porque incluyen elementos culturales que enfocaban diferente a la noticia mientras que los noticieros mexicanos deprimen porque sólo trasmiten robos, asaltos y asesinatos. Elementos que abordamos desde la lógica de oposición renglones arriba. Esta oposición en la percepción del grupo, evoca una realidad televisiva que trasmite inseguridad y violencia en México, ya que en Estados Unidos, las noticias de asalto y asesinato son un escándalo allá. Lo que no implica una credibilidad total sobre la televisión norteamericana, ya que «muchos quieren hacer creer que si se oye en inglés es verdad».

\section{CONCLUSIONES}

Resulta de particular relevancia la disyuntiva que perciben los jóvenes sobre la oferta televisiva en la frontera a partir de la entretención, eje que articula y fractura elementos de gratificación humorística: lo norteamericano y lo mexicano. Esta disyuntiva implica una doble competencia, donde opera el factor frontera, desde el cual se aprecian dos sistemas nacionales televisivos. Esta doble competencia televisiva implica, al final de cuentas que «crecer viendo televisión en inglés», también quiere decir crecer viendo televisión en español. 
Los jóvenes televidentes confirman la legitimidad de la televisión estadounidense porque permite mayor uso lúdico, educativo, estratégico y pragmático que la televisión mexicana. Esto implica adquirir cosmovisiones foráneas, y a su vez, competencias culturales en la negociación «equilibrada» de significados. Las consecuencias reconocibles son la afirmación del lugar-frontera que se ocupa para vivir y la fragmentación (o porosidad) que tiende a diferenciar las prácticas de televidencia. Es evidente que la legitimación televisiva estadounidense es relevante en la frontera porque emerge de justificaciones provenientes de comparaciones, no siempre discontinuas (lo discontinuo se opone al determinismo), sobre todo de aquellas donde se define «lo propiamente mexicano» y «lo estadounidense». Esto explica de cierta manera que el tipo de formulaciones realizadas por los tijuanenses son siempre desde una «mexicanidad» , mejor dicho, «tijuanidad».

En este juego de oposiciones intensas, la disyuntiva formula una tensión que comienza a experimentarse en la frontera con la audiencia joven. ¿Dónde invertir la significación de los mensajes televisivos en un lugar donde se necesita sobrevivir bajo varias lógicas de naciones? Una respuesta, todavía parcial e incipiente, formulada por Renato Ortiz insta a pensar sobre la audiencia planetaria:

no «todos» están interesados por los programas «mundiales» pero circulan en un «estrato juvenil que trasciende fronteras nacionales. Su importancia reside en el hecho de que generan un espacio de legitimidad de una cultura internacional-popular (1998: 96).

Esta categoría de «espacio de legitimidad de una cultura internacional-popular» busca articular una nueva comprensión de los fenómenos sociales, aunque muy abierta e incompleta (pienso también en el concepto de supercultura de James Lull) tiene el mérito -como señala el propio autor- de revitalizar el pensamiento y de promover otro tipo de estudios.

En función de otros medios de comunicación, la televisión estadounidense apuesta a lo mundial no sólo en términos de contenido sino de formato y género. Así, se pueden ver claramente las implicaciones que 
estos procesos han tenido en México (en cuanto a tecnología, modelo comercial y género), y en especial, en la frontera. La televisión norteamericana es una industria que dinamiza económicamente el entorno trasnacional (publicidad, mercadotecnia, deporte, música, entre otros); olvidar esto es no asumir la complejidad de su naturaleza comercial. Pero también cultural, la televisión es un foro y dispositivo de sueños de la que casi nadie se sustrae. Así lo han mencionado infinidad de autores que han realizado estudios sobre este medio. La «fábrica de sueños « que encaja con las consecuencias comerciales y televisivas de los deseos y aspiraciones de la audiencia.

\section{Bibliografía}

ALEGRÍA, Tito (1992) Desarrollo urbano en la frontera México-Estados Unidos. México: CONACULTA.

Bustamante, Jorge (1989) «Frontera México-Estados Unidos; reflexiones para un marco teórico». En Frontera Norte. Vol. I, núm. 1. Enero-junio.

GARCía Canclini, Néstor (1990) Culturas híbridas. México: Grijalbo.

GIDDENS, Anthony (1994) Consecuencias de la modernidad. Madrid: Alianza.

- (1995) La constitución de la sociedad. Bases para la teoría de la estructuración. Buenos Aires: Amorrortu.

IBARRA, Armando (1998) «La agenda televisiva infantil en Guadalajara». En Comunicación y sociedad, 32. Guadalajara: UdeG.

JENSEN, Klaus Brunh (1987) «Qualitative audience research: toward an integrative approach to reception». En Critical studies in mass communication, 4. Estados Unidos.

JUÁREZ, Rosa Esther (1992) Las chapuzas del lector. Análisis semiótico de la recepción. Guadalajara: ITESO.

Lozano, José Carlos (2000) «Oferta y consumo de contenidos televisivos transnacionales en México». En Estudios sobre las culturas contemporáneas. Época II, vol. VI, núm. 12. Colima: Universidad de Colima.

LuLL, James (1997) Medios, comunicación, cultura: aproximación global. Buenos Aires: Amorrortu.

ORTIZ, Renato (1998) Otro territorio. Bogotá: Convenio Andrés Bello. 
REGUILLO, Rossana (1995) En la calle otra vez. Las bandas: identidad urbana y usos de la comunicación. Guadalajara: ITESO.

SÁNCHEZ Ruiz, Enrique (1996) «El nuevo carácter de la dependencia: globalización y el espacio audiovisual». En Guillermo Orozco (comp.) Miradas latinoamericanas a la televisión. PROIICOM, 2. México: Universidad Iberoamericana.

VALENZUELA Arce, José Manuel (1993) «Ámbitos de interacción y consumo cultural en los jóvenes». En García Canclini (coord.) El consumo cultural en México. México: CONACULTA.

Fecha de recepción: 18/04/05. Aceptación: 18/07/2005. 